\title{
Realidade Aumentada no Margs: Impressões de um Experimento
}

\author{
André Luis Marques da Silveira, PGIE/UFRGS, UNIRITTER \\ andre@um.pro.br \\ Maria Cristina Villanova Biazus, PGIE/UFRGS \\ cbiazus@ufrgs.br \\ Margarete Axt, PGIE/UFRGS \\ maaxt03@gmail.com
}

\begin{abstract}
Resumo: Este artigo descreve um experimento realizado com o sistema informatizado "Diálogos". O experimento envolveu um grupo de estudantes de Licenciatura em Artes Visuais, estudantes do Ensino Médio, o Museu de Arte do Rio Grande do Sul Ado Malagoli, e os visitantes da exposição "Stockinger: os diversos tempos da forma". A partir de atividades realizadas em laboratório de informática, os estudantes se expressaram em relação às obras em exposição. Após, os registros foram expostos no museu, através da tecnologia de Realidade Aumentada.
\end{abstract}

Palavras-chave: Arte/educação, Bakhtin, Tablet Museu e Realidade Aumentada

\section{Augmented Reality at Margs: Experiment Impressions}

\begin{abstract}
This article describes an experiment conducted with the computer system "Dialogues". The experiment involved a group of Bachelor students in Visual Arts, High School students, the Art Museum of Rio Grande do Sul Ado Malagoli, and visitors of the exhibition "Stockinger: various times of the form". From activities in computer lab, the students expressed their opinions about works on exhibition. After it, the records were exposed in the museum, through the Augmented Reality technology.

Key words: Art/education, Bakhtin, Tablet Museum, Augmented Reality
\end{abstract}

\section{INTRODUÇÃO}

O sistema "Diálogos" é um software que permite gerenciar o acervo de um museu e registrar as percepções do público visitante em relação às obras em exposição. $\mathrm{O}$ registro ocorre através de atividades conduzidas por professores da rede de ensino ou mediadores do museu. A atualização do sistema pode ser feita a distância ou no local da exposição, através de computadores ou dispositivos portáteis ${ }^{1}$ conectados à Internet. Para proceder à visualização dos registros do público no espaço expositivo da mostra, o sistema adota a tecnologia de Realidade Aumentada (RA). Segundo MILGRAM e KISHINO (1994), a RA busca gerar um cenário amplificado por informações adicionais, composto por uma combinação de uma cena real e uma cena virtual gerada pelo computador. Para o processamento de combinação das cenas, pode-se proceder através do uso de Global Positioning System (GPS) ou técnicas de visão baseadas em elementos fixos existentes no cenário.

O sistema "diálogos" utiliza uma câmera (Webcam) para capturar Marcadores Fiduciais (Fiducial Tags) previamente inseridos e posicionados próximos ou acima dos

\footnotetext{
${ }^{1}$ Ness a classificação encontramos o PDA (Personal Digital Assistant), Smartphone e Tablet.
} 
objetos reais em exposição. Após a captura, ele extrai dados de localização, orientação e identificação do marcador. Depois, a cena real é mixada com os objetos virtuais gerados pelo sistema. Um Marcador Fiducial é semelhante a um código de barras visual projetado com a intenção de ser facilmente reconhecido por um sistema de leitura informatizado. No nosso cotidiano, podemos observar tecnologias similares, tais quais os códigos de barras dos produtos comercializados nas lojas de supermercado. A principal diferença entre eles é que o código de barras não reconhece a posição espacial do marcador em relação ao mundo.

Foram testados diversos Frameworks com o intuito de capturar e reconhecer um marcador presente no cenário e após mixar a cena real aos dados provenientes do sistema "Diálogos". Os Frameworks testados foram: Andar ${ }^{2}$, Ezaflar", Flarmanager ${ }^{3}$, Nyartoolkit ${ }^{5}$ e Qualcomm ${ }^{6}$. Todos eles apresentaram dificuldades das mais diversas ordens para proceder às visualizações. Destacamos a principal dificuldade, a portabilidade, ou seja, a característica da aplicação de ser executada em outras plataformas ou sistemas operacionais. $\mathrm{Na}$ figura abaixo podemos acompanhar $\mathrm{o}$ resultado de uma visualização em RA.
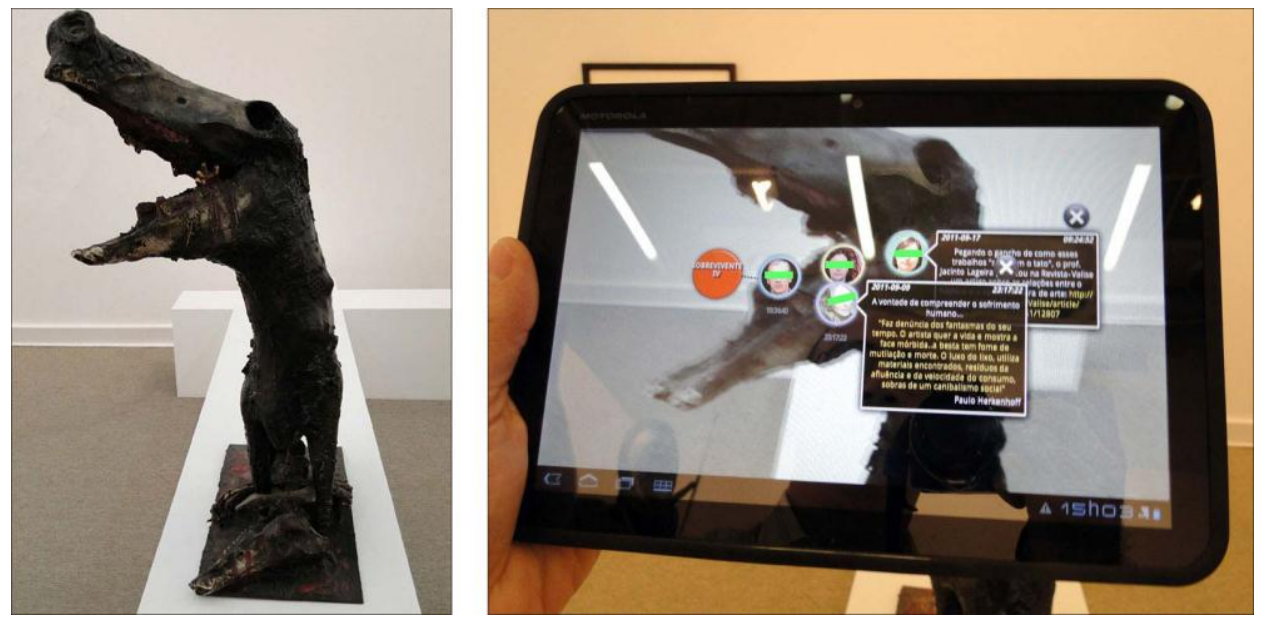

Figura 1 - Imagem demonstrando uma visualização em RA.

\section{OS RECURSOS DISPONÍVEIS NO SISTEMA}

Para a concepção e modelagem do sistema adotamos a metodologia descrita no HMT ("Hypermedia Modeling Technique"), desenvolvida por NEMETZ (1995). A seguir descrevemos os recursos mais relevantes do sistema.

As classes museu, escola e usuário permitem o cadastro dos locais de exposição das obras de arte, de escolas e de usuários. Nelas encontramos, por exemplo: nome, endereço, texto de apresentação e mapa do museu; nome, endereço, texto de apresentação da escola; nome, foto, idade dos usuários. A classe sinal contém o registro das técnicas de visualização adotadas pelo sistema, contemplando as seguintes formas de registro: fiducial tag, keycode, latitude, longitude, altitude e situação. Nas classes artista e obra encontramos informações, tais como: nome, descrito, foto do artista; título, imagem, altura, largura da obras. A classe multimídia possui registros verbais e não

\footnotetext{
${ }^{2}$ Disponível em: <http://code.google.com/p/andar> Acesso: Fev 2011.

${ }^{3}$ Disponível em: <http://www.ezflar.com> Acesso: Fev 2011.

${ }^{4}$ Disponível em: <http://words.transmote.com> Acesso: Fev 2011.

${ }^{5}$ Disponível em: <http://nyatla.jp/nyartoolkit> Acesso: Jan 2011.

${ }^{6}$ Disponível em: <http://developer.qualcomm.com> Acesso: Jan 2011.
}

V. $9 \mathrm{~N}^{\mathrm{o}}$ 2, dezembro, 2011 
verbais sobre as obras ou artistas. As informações geradas pelo sistema, tais como obras e dados de multimídia apontam para a classe sinal. Na figura 2 podemos visualizar duas telas do sistema, a saber: tela de abertura e cadastro de atividade.

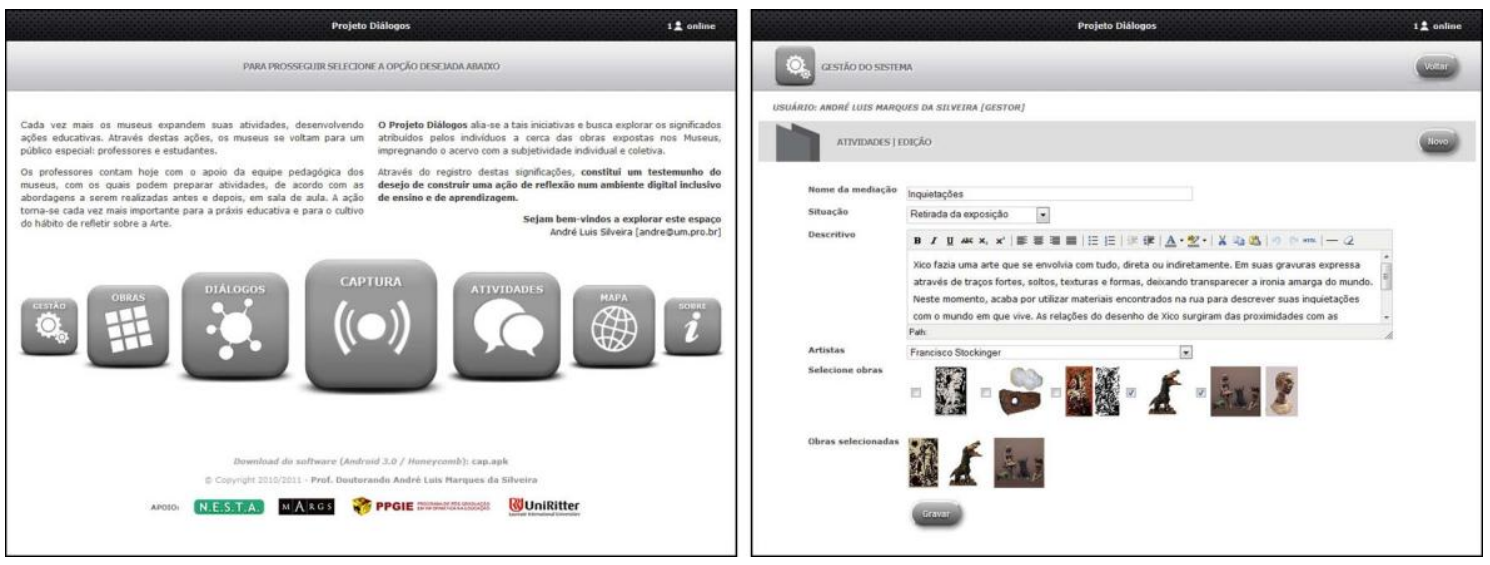

Figura 2 - Tela de abertura do sistema e cadastro de atividade.

A classe atividade estabelece os limites do diálogo do grupo. Após definirmos o título e o objetivo da atividade, selecionamos as obras e artistas que serão objeto da investigação. A classe atividade define as obras e os artistas que serão trabalhados, a classe rota discursiva restringe as manifestações dos estudantes a uma obra préselecionada. A partir dela são estabelecidos vínculos com os enunciados dos participantes. Para BAKHTIN (2006, p. 293), o enunciado é a unidade da comunicação verbal que permite tratar a linguagem como movimento de interlocução real entre sujeitos falantes. Ele é um ato de linguagem cujos contornos propiciam que o outro realize uma apreciação valorativa com relação àquilo que falamos ou escrevemos.

As classes acima definidas e a forma com que estabelecemos as associações entre elas permitem que seja criada uma atividade que abrange um ou mais autores e suas respectivas obras. Ao criarmos uma atividade, podemos optar por tomar uma ou mais obras de um único artista como objeto de investigação, vinculando, assim, o recorte à produção deste sujeito, ou optar por efetuarmos um diálogo mediante um recorte que não envolve apenas um único artista, mas um grupo de artistas e suas respectivas obras.

\section{O MÓDULO DE VISUALIZAÇÃO}

A partir dos enunciados gravados no sistema, vislumbramos uma arquitetônica dialógica. Segundo AXT (2011), uma arquitetônica não é uma estrutura presente ou préestabelecida nos enunciados, mas uma conjuntura particular compromissada com a produção de sentido no mundo. Em determinados momentos, esses mundos constituídos de consciências que agem, comunicam-se e se interpenetram. Associações, deduções, induções, generalizações, sínteses, acréscimos, dentre outras operações inferenciais emergem desse encontro. Este ideal abandona as propostas de explicar ou transferir o conhecimento estético sobre arte para o público do museu. Ao contrário, propõe uma mobilização de diversas arquitetônicas que formariam estratos de sentido, superpostos a obra, constituindo uma dialogia que referencia a trajetória histórica da obra.

A dialogia ou dialogismo é o princípio constitutivo da linguagem. Segundo FIORIN (2006, p. 167), "isto quer dizer que o real se apresenta para nós semioticamente, o que implica que nosso discurso não se relaciona diretamente com as coisas, mas com outros discursos, que semiotizam o mundo". O dialogismo compreende 
as relações semânticas entre toda a espécie de enunciados na comunicação discursiva e se dá sempre entre discursos.

Optamos por apresentar os enunciados das atividades através de uma topologia rizomática. Em botânica, o rizoma compreende uma ramificação própria de algumas plantas que brota de qualquer ponto da planta. No sistema, adotamos o conceito na sua forma literal e não metafórica. Em uma atividade, brotam ramificações a partir das rotas discursivas. No centro da ramificação, encontramos o objeto da investigação (obra). Além disto, uma atividade pode ser composta por mais de uma obra $\mathrm{e}$ conseqüentemente novas estruturas que se interconectam. Da mesma forma, as atividades também se interconectam. Estas ligações, entre as atividades e obras, se dão de maneira linear e não hierárquica. Os enunciados se ramificam a partir das rotas discursivas, tendo em vista o locutor e o interlocutor. $\mathrm{Na}$ figura 3 podemos acompanhar o procedimento.

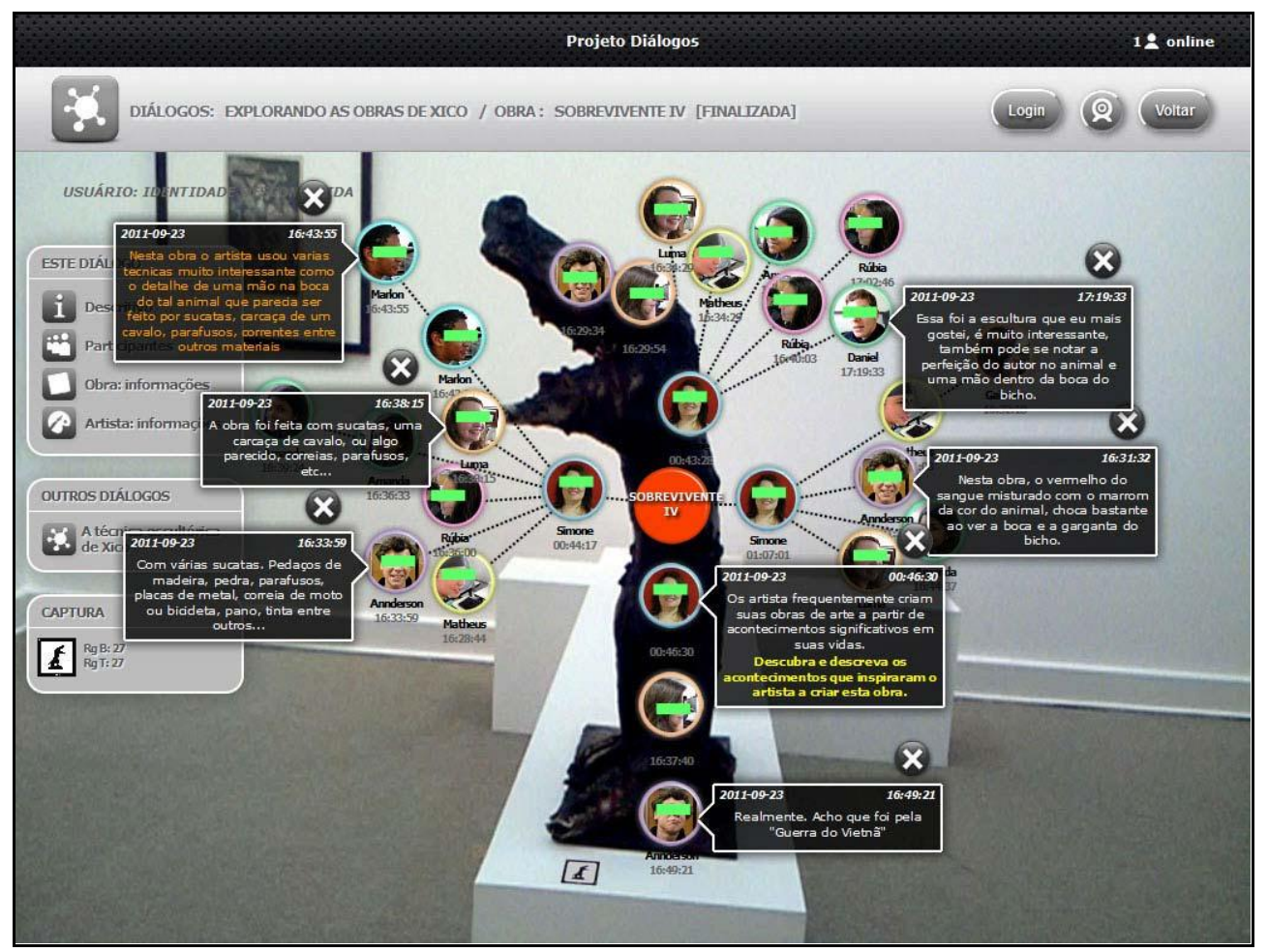

Figura 3 - Topologia rizomática dos enunciados de uma atividade.

A figura 4 apresenta a forma de interação do usuário, através do toque sobre qualquer nó da estrutura do rizoma, é apresentado o conteúdo do enunciado ou da rota, dentro de um balão de comunicação. Sobre o balão são apresentados botões que propiciam alterar, incluir, excluir ou fechar um enunciado. 


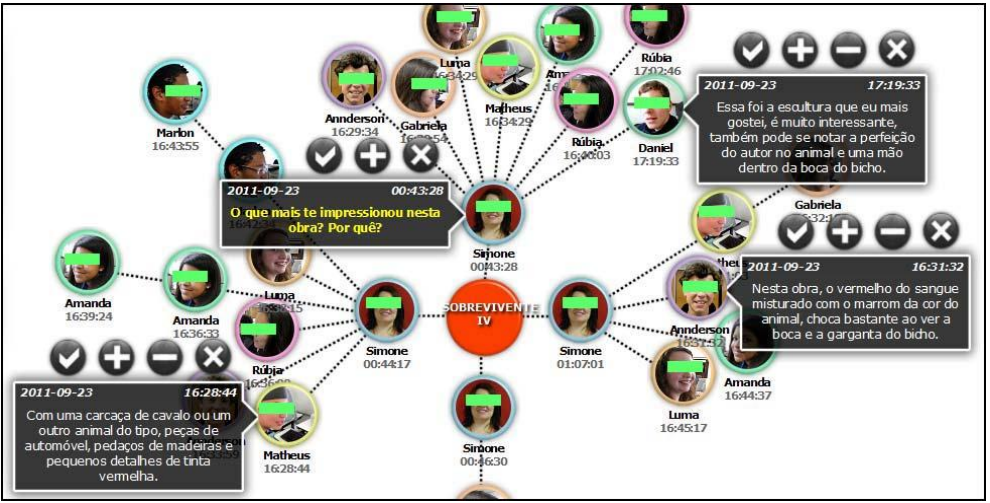

Figura 4 - Botões: alterar, incluir, excluir ou fechar os enunciados.

Quando da inclusão de um enunciado o participante escolhe o tipo de linguagem.

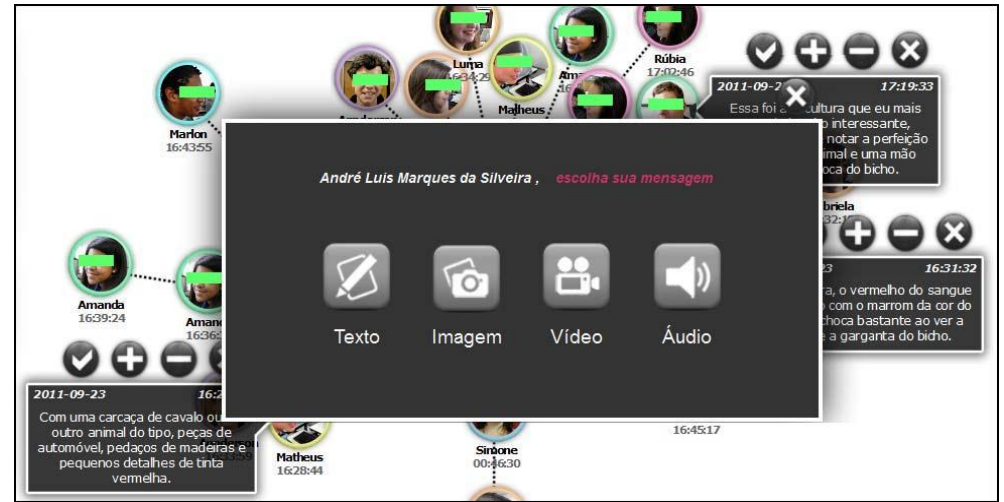

Figura 5 - Opções de seleção do tipo de linguagem (texto, imagem, vídeo ou áudio).

A seguir descrevemos o experimento realizado através do uso do sistema. Ele teve como objetivo realizar uma atividade dialógica em condições reais de uso do sistema, disponibilizar os dados gerados no espaço expositivo de um museu, coletar e analisar as impressões do público visitante da exposição. Neste artigo, não iremos analisar os enunciados proferidos pelos participantes, mas apresentaremos dados referentes às impressões do público que visitou a mostra onde os registros foram expostos em RA.

\section{O EXPERIMENTO REALIZADO}

O experimento envolveu estudantes do curso de Licenciatura em Artes Visuais da Universidade Federal do Rio Grande do Sul, durante a disciplina denominada Laboratório de Informática e Ensino das Artes Visuais. Também contou com a participação de uma turma do primeiro ano do Ensino Médio da disciplina de Artes Visuais do Colégio Aplicação da UFRGS, do Museu de Arte do Rio Grande do Sul Ado Malagoli e dos visitantes da exposição "Stockinger: Os Diversos Tempos da Forma". $\mathrm{Na}$ imagem abaixo, podemos visualizar os estudantes do Colégio Aplicação visitando a exposição. 

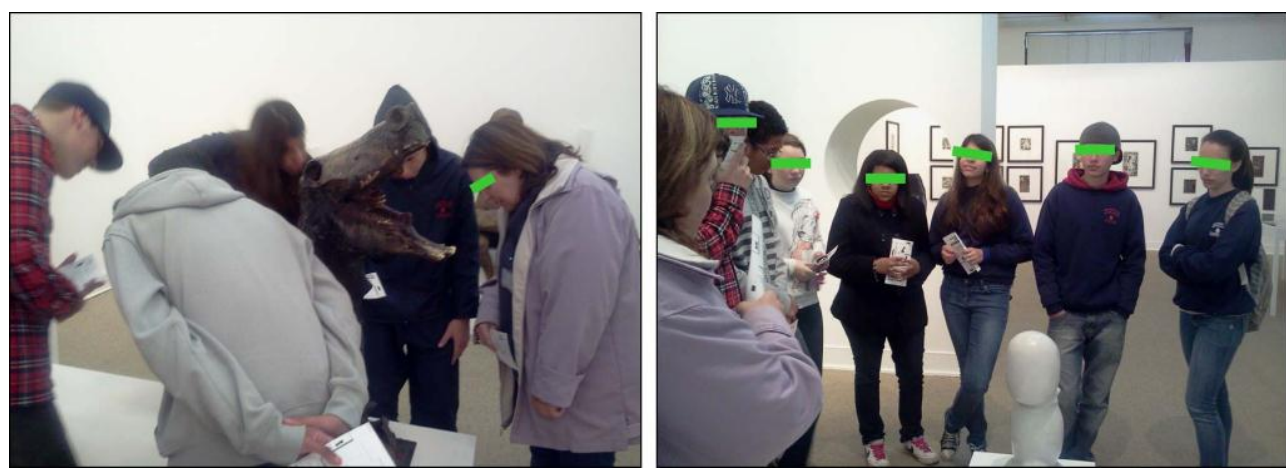

Figura 6 - Estudantes do colégio Aplicação visitando a exposição

As etapas do experimento compreenderam: apresentação do projeto ao Diretor do MARGS, solicitação de autorização para sua realização, definição da exposição, apresentação do projeto aos professores e estudantes, visitas a exposição, instrumentalização dos participantes, montagem de planos de ensino, cadastros no sistema, realização de atividades, exposição dos enunciados gravados no sistema no espaço da mostra e coleta das impressões do público visitante da exposição.

A imagem a seguir ilustra uma atividade dialógica realizada no laboratório do Colégio Aplicação da UFRGS. Durante e após a atividade, os registros gravados pelos estudantes podiam ser acessados no próprio espaço expositivo do museu.
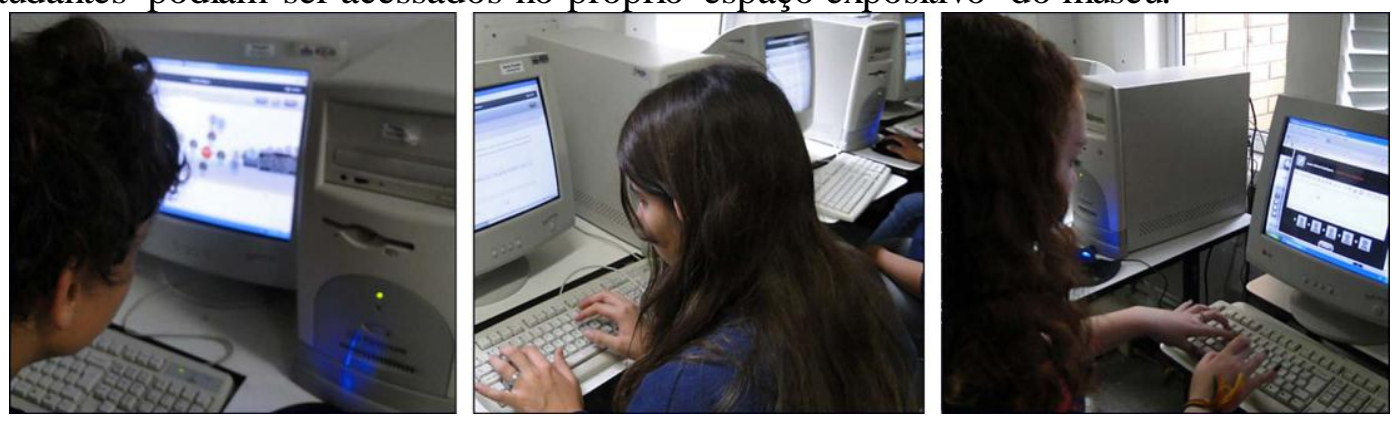

Figura 7 - Estudantes do colégio Aplicação realizando uma atividade em laboratório.

\section{SOBRE A EXPOSIÇÃO}

A exposição se caracterizava como monográfica e apresentava uma visão panorâmica de cerca de 50 obras do artista Francisco Stockinger, pertencentes ao acervo do MARGS. Ela ocupava três salas do museu. Na Galeria "Oscar Boeira" estavam expostas principalmente esculturas. $\mathrm{Na}$ Galeria "Pedro Weingärtner" estavam expostas xilogravuras do artista e duas esculturas, uma em pedra e outra em ferro e madeira. Estas obras, pela proximidade com a sala ao lado, Galeria "Ângelo Guido", buscavam cumprir a função de "transição do olhar" para as próximas obras expostas, compostas em sua totalidade por esculturas em pedra, gesso e ferro. Um artifício adotado pelo curador, como um sinal de alerta e convite ao olhar, foi à adoção de ícones. Eles estavam fixados nas paredes das salas e sua localização não respeitava a organização das obras expostas por salas. Antes, cumpriam a função de reforçar a comunicação com o público (indicial), convidando o visitante a explorar as demais salas. Aproveitando esta feliz coincidência, adotamos alguns dos ícones já existentes e criamos outros para serem utilizados como marcadores do sistema. Para distingui-los dos demais, uma borda em preto foi criada. Diferente da forma até então utilizada, os marcadores foram posicionados próximo às obras que eles representavam. 

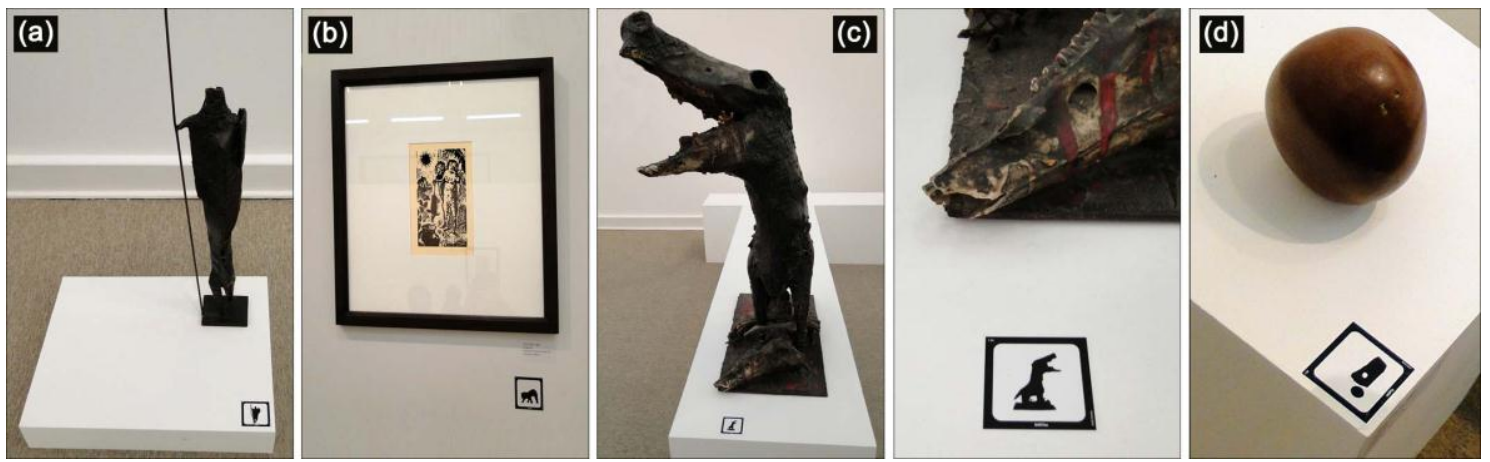

Figura 8 - Exemplo de marcadores (fiducial tags) aplicados na exposição

(a) Guerreiro, (b) Xilogravura homem Gabiru (c) Sobreviventes e (d) As pedras

Durante três dias do mês de setembro de 2011, o sistema "Diálogo" foi utilizado no Museu de Arte do Rio Grande do Sul Ado Malagoli. Cinquenta e dois visitantes utilizaram o recurso no espaço da mostra. A partir de dois Tablets - Samsung Galaxy TAB P1000 e Motorola XOOM -, eles interagiram com o sistema. Quarenta e cinco pessoas preencheram um formulário com seus dados pessoais e impressões sobre o uso do recurso.

\section{AS IMPRESSÕES DOS VISITANTES}

A faixa etária dos participantes foi bastante diversificada, 51\% deles se encontram na faixa etária de 20 até 34 anos de idade. Tendo em vista toda a amostra, o público feminino predomina com 58\%; o masculino, com 42\%. Na escolaridade do público, predominam as séries, superior incompleto (18\%), superior completo (33\%) e especialização (13\%). Os três graus de escolaridade somados compreendem $64 \%$ do público. Em relação à profissão, podemos perceber que $27 \%$ do público é formado por estudantes, $18 \%$ por professores, perfazendo um total $44 \%$ da amostra.
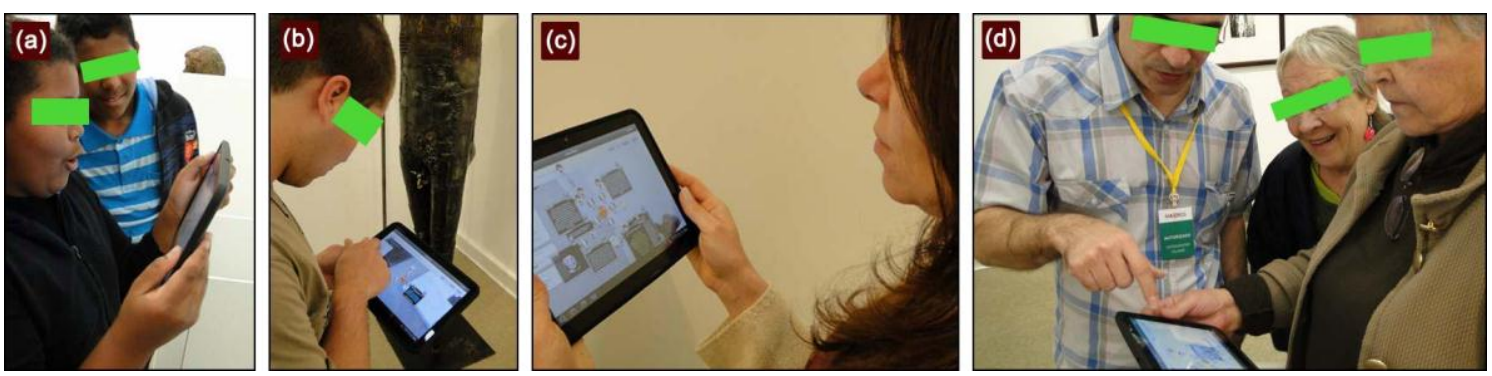

Figura 9 - Público visitante da exposição acessando os enunciados no MARGS.

(a) Crianças, (b) Jovens (c) Adultos e (d) Idosos.

Para procedermos à análise das impressões do público, utilizamos a técnica de Análise de Conteúdo, de acordo com a autora Laurence Bardin (1977). A classificação das impressões em categorias impôs uma investigação do que cada uma delas possui em comum, caracterizando-se por ser um processo do tipo estruturalista (BARDIN, 1977, p.118). O que caracterizou este momento de análise foi o fato da inferência ser fundada na presença de índices, tais como tema, palavra, e não na mensuração quantitativa da sua aparição em cada enunciado. A partir da análise das impressões, concebemos as seguintes categorias: quanto à proposta do sistema, quanto aos diálogos em rede, quanto às informações oferecidas, quanto à experiência de uso/aplicação, quanto à interatividade/interação, quanto à interface e quanto à tecnologia.

\subsection{Quanto à proposta do sistema}

V. $9 \mathrm{~N}^{\mathrm{o}}$ 2, dezembro, 2011 
Esta categoria se relaciona à concepção de um serviço que foi projetado e ofertado ao público em geral. Compreende a impressão de inovação, ineditismo e demais expressões emocionais dos usuários em relação ao mesmo. Destacamos abaixo dois enunciados desta categoria. Em geral, os enunciados apresentam uma justificativa para o juízo do visitante.

MUITÍSSIMO INTERESSANTE. Amplia e enriquece a experiência. A obra ganha contextos e camadas. ENRIQUECE A EXPERIÊNCIA DO PÚBLICO. Adiciona um contexto histórico e social que torna a experiência cultural mais agradável e permanente.

INÉDITO PARA MIM. Parece-me que é uma INICIATIVA QUE VAI ALÉM DA SALA, DOS MUROS DO MUSEU. Garante, ou garantiria, um aprofundamento sobre o artista e cada uma de suas obras, aqui em exposição. Além, é claro de proporcionar uma INTERAÇÃO VIRTUAL COM PESSOAS que participaram da visita à exposição.

Para o público, a concepção do sistema se justifica em razão dos ganhos percebidos durante o processo de interação vivenciado, tais como: informações ofertadas, expansão das fronteiras do museu, interação entre pessoas, dentre outros.

\subsection{Quanto aos diálogos em rede}

Esta categoria compreende as impressões dos visitantes que apontam para as seguintes noções: aprofundamento, aproximação, compartilhamento, debate, diálogo e discussões. Nesta categoria buscamos investigar o aspecto dialógico por nós almejado. Destacamos abaixo dois enunciados da categoria.

COLABORATIVO E INSTANTÂNEO. Ferramenta extremamente útil para auxiliar no processo de disseminação de arte e cultura, GERANDO TROCAS ENTRE DIVERSOS E DISTINTOS OLHARES

É a tecnologia aproximando o público da arte a partir de uma REDE SOCIAL.Traz informações fundamentais e permite A TROCA DE IDEIAS, O DIÁLOGO, A INTERAÇÃO ENTRE AQUELES QUE VISITAM A EXPOSIÇÃO COM OUTRO, ATÉ ENTÃO (DES) CONHECIDOS

Nos enunciados da categoria identificamos a importância dada ao processo de aprendizagem colaborativo em rede, que propicia trocas, que aproxima os indivíduos, que provoca olhares distintos.

\subsection{Categoria: Quanto às informações oferecidas}

Esta categoria se relaciona tanto aos dados informativos sobre o artista, as obras, a localização das obras no museu, dados de multimídia, dentre outros, quanto aos diálogos gravados pelos participantes de atividades de mediação. Está relacionada ao acesso, leitura ou visualização dos enunciados verbais e não verbais gravados no sistema.

O enunciado abaixo, de uma professora de 29 anos de idade, residente na cidade de Niterói, no Rio de Janeiro, enfatiza sua posição quanto às informações ofertadas. $\mathrm{Na}$ sequência de seu enunciado, os elementos gramaticais "A PARTIR DE ... QUE ..." estabelecem as condições para esta oferta, ou seja, de AUXÍLIO. Na perspectiva teórica adotada para o sistema "Diálogos", a palavra "auxílio" está relacionada ao desenvolvimento cognitivo resultante da interação entre pessoas. A interação entre sujeitos nas atividades de diálogos pode colaborar para o desenvolvimento cognitivo, tanto dos sujeitos das atividades, quando do público visitante. Ao término, a professora julga as informações ofertadas: "CONSEGUE". 
TODAS AS formas desenvolvidas e disponíveis PARA difusão da informação, sobretudo das informações culturais, SÃO es senciais para uma educação baseada em valores humanistas e humanitários. Possibilitando o acesso às informações acerca das obras de arte em exposição, A PARTIR de equipamentos QUE auxiliam a compreensão pelo expectador, esse aplicativo CONSEGUE TRAZER maior profundidade de conteúdo sobre os temas expostos.

Os demais enunciados da categoria apontam para as seguintes noções: fornece informações fundamentais sobre o artista e as obras em exposição; vasto número de informações; recurso para obter informações, muito informativo, informações rápidas; permite aprofundar conhecimentos teóricos, sana dúvidas sobre as obras, bastante completo para entendimento maior das obras.

\subsection{Categoria: Quanto à experiência de uso / aplicação}

Esta categoria se relacionada tanto à experiência de manipulação do sistema, quanto aos possíveis benefícios de seu emprego e facilidade de uso. Compreende os enunciados que apontam para as seguintes noções: auxilia a compreensão, chama a atenção, contextualiza, potencializa, estabelece relações, dentre outros.

As seguintes impressões do público foram associadas ao sistema "Diálogos": recurso a serviço da cultura; educativo; a serviço da difusão de informação culturais; para visitas individuais; enriquece a experiência do público; favorece o crescimento cultural; recurso abre novos espaços de reflexão; desperta o interesse pela arte nos mais jovens; propicia discussão sobre os temas que podem fugir do que retrata as figuras, indo além; facilita a compreensão da obra; aprofundar conhecimentos teóricos.

$\mathrm{O}$ enunciado abaixo, de uma senhora de 76 anos de idade, médica, apresenta um ponto de vista que diverge dos demais: "ACHEI" o recurso "MUITO" prático e fácil de ser usado. Após, relativiza e julga: "EMBORA" devido minha idade, "GOSTO MUITO" de contato pessoal. Em outras palavras, a visitante achou o recurso prático e fácil de usar, mas não pretende utilizá-lo, pois prefere o contato com os mediadores.

ACHEI o recurso MUITO prático e fácil de ser usado, EMBORA devido minha idade, GOSTO MUITO de contato pessoal COM os mediadores. Obrigada pela experiência

A partir deste enunciado, devemos frisar que o sistema não pretende ser um substituto dos mediadores dos museus, mas colaborar com estes e outras ações educativas pré-existentes.

\subsection{Quanto à interação / interatividade}

Devemos considerar que o termo interação é muito abrangente, permitindo que pensemos a interação entre os sujeitos que participaram das atividades, gravando enunciados verbais e não verbais; entre o público visitante e os enunciados no sistema; entre as pessoas e a interface do software; entre as pessoas e o dispositivo de hardware (Tablet). Nesta categoria, relacionamos as impressões do público quanto às relações dialógicas entre as pessoas, a interação entre as pessoas e o conhecimento, a interação entre os sujeitos num diálogo sobre as artes. Abaixo apresentamos um enunciado que exemplifica a percepção do publico.

RECURSO COLABORATIVO E INSTANTÂNEO, proporcionar uma INTERAÇÃO VIRTUAL COM PESSOAS, entre aqueles que visitam a exposição, te coloca numa rede, LIGADO COM OUTROS. 


\subsection{Quanto à interface}

Esta categoria está relacionada tanto a representação gráfica criada para o sistema, quanto aos modelos de interface adotados. Compreende a impressão de facilidade e rapidez de entendimento, simplicidade de uso, clareza, limpeza e atração visual. Abaixo apresentamos dois enunciados que são representativos da percepção do publico.

FÁCIL DE USAR e compreende com a INTERFACE, LIMPEZA VISUAL (...)

INTERFACE DE FÁCIL utilização, com BOA NAVEGAÇÃO (...)

Destacamos que o sistema utiliza indicativos de tela do tipo janelas, ícones, menus e ponteiros, o que caracteriza o modelo Interfaces gráficas de Usuário. Também busca explorar as características próprias do Tablet, tela sensível ao toque. Mediante a manipulação direta de objetos no mundo real (Marcador fiducial) adota também o modelo de Interfaces Tangíveis de Usuário. Uma interface tangível é uma interface física de ambiente através da qual uma pessoa interage com a informação digital.

\subsection{Quanto à tecnologia}

Esta categoria se relaciona ao uso do Tablet no experimento e à velocidade de acesso aos dados gravados no sistema. Durante o experimento, disponibilizamos dois modelos de Tablets: Samsung Galaxy TAB P1000 e Motorola XOOM. Devido às características específicas do Motorola XOOM, principalmente o tamanho e resolução da tela, a velocidade do processamento, a manipulação touch screen, ele se mostrou mais eficaz. No enunciado abaixo, identificamos este aspecto, apesar de ele estar também vinculado ao uso da interface do sistema.

(...) sabe o TABLET, o programa - software, em si É FÁCIL de usar e dinâmico de usar.

Para acesso às informações gravadas no sistema "Diálogos", armazenadas em um servidor na Internet, testamos a tecnologia móvel $3 G$ de três operadoras de celular de Porto Alegre. A principal diferença percebida entre elas era a velocidade de acesso à internet e a oscilação do sinal. No último dia do experimento, apenas uma operadora mantinha o serviço habilitado.

\section{CONCLUSÕES PRELIMINARES}

Entendemos que os enunciados gravados no sistema "Diálogos" espelham o caráter ativo e responsivo dos participantes e fundamentam a noção por nós defendida da língua como atividade. A partir de dois Tablets os visitantes da mostra tiveram a oportunidade de acessar estes registros. Após, deixaram suas impressões sobre a experiência vivenciada. O corpus para análise compreendeu 45 enunciados registrados por escrito em um formulário. Cabe ressaltar que registramos durante o evento, 1830 visualizações de páginas. Nas falas do público, identificamos a importância dada à atividade de mediação em museu. Entendemos que a proposta do sistema foi compreendida, e que o seu uso se justifica em função dos ganhos percebidos durante a visita, tais como: informações ofertadas, expansão das fronteiras do museu, interação entre pessoas, enriquecimento da experiência, troca de ideias, diálogos entre diversos e distintos olhares sobre a exposição, dentre outros. Na busca de uma compreensão sobre uma obra de arte, os estudantes, os professores e o público do museu se envolveram num ato dialógico responsável com a obra de Francisco Stockinger. É justamente aí que reside a possibilidade do encontro do outro, o qual, para Bakhtin (2006, p. 377-378), é o momento maior da compreensão. Através desses encontros, vislumbramos relações 
dialógicas, atentos à polissemia da vida e às possibilidades de sua reinvenção. Entendemos que os enunciados proferidos em uma atividade formam uma conjuntura particular de enunciação, na qual identificamos situações em que os participantes, expressam entonações pessoais que valoram e ideologizam as palavras e as réplicas. Esta conjuntura é definida por um determinado espaço-tempo histórico, contextualizado, podendo ser perspectivado e valorado, composto de centros de valores diferindo entre si, moventes e mutantes. Neste contexto, as atividades realizadas e registradas foram muito valiosas. Consideramos que a obra de arte convida o espectador, não apenas a ouvir e observar, mas a participar e se envolver. O confronto de ideias, a imaginação, enriquece o sujeito e mexe com o sentimento acerca dos signos imagéticos.

\section{REFERÊNCIAS BIBLIOGRÁFICAS}

AXT, Margarete. Mundo da vida e pesquisa em educação: ressonâncias, implicações, replicações. Letras de Hoje, Porto Alegre, v. 46, n. 1, p. 46-54, jan./mar. 2011.

BAKHTIN, Mikhail. Estética da criação verbal. São Paulo: Martins Fontes, 2006.

BARDIN, Laurence. Análise de conteúdo. Rio de janeiro: Edições 70, 1977.

FIORIN, José Luiz. Interdiscursividade e intertextualidade. In: BRAIT, Beth (Org). Bakhtin: outros conceitos-chave. São Paulo: Ed. Contexto, 2006. P. 161-193.

MILGRAM, Paul, KISHINO, Fumio. A Taxonomy of Mixed Reality Visual Displays. IEICE Transactions on Information Systems, Vol E77-D, No.12 December 1994.

NEMETZ, Fábio. HMT: Modelagem e projeto de aplicações hipermídia. Dissertação de Mestrado, CPGCC-UFRGS, 1995.

SILVEIRA, André L. Marques. BIAZUS, M. C. V. A Realidade Aumentada aplicada à Museologia. In: VI Colóquio de pesquisa - VI SEPesq, Porto Alegre: UniRitter, set./out. 2010. 